\title{
Modeling Migration of Cs-137 in Sewer System of Fukushima City Using Model for Radionuclide Migration in Urban Environment and Drainage System (MUD)
}

\author{
M. A. Pratama, M. Yoneda, Y. Yamashiki, Y. Shimada, and Y. Matsui
}

\begin{abstract}
Following Fukushima Daiichi Nuclear Power Plant accident, Cs-137 has entered sewer system of Fukushima City which was confirmed by detection of the radionuclide in dewatered sludge of waste water treatment plant (WWTP). Consequently, the sludge could not be transported to landfill facility due to radioactive content. Conducting simulation on migration of Cs-137 from urban area into WWTP becomes the objective of this study. MUD, a compartment model consisted of urban and WWTP sub model was used in this study. Migration process is simulated based on natural process and decontamination activities. Value of the parameters used in this study is combination between default general value and site specific value. The result of the model showed an agreement with observed data with $85 \%$ of the data in range of $10-90$ percentiles of observed data. Value of $R^{2}$ between modeled and observed data about 0.84 shows the model could explain the seasonal variation occurred in real condition.
\end{abstract}

Index Terms-Migration of Cs-137, sewer system, urban.

\section{INTRODUCTION}

An earthquake with 9.0 Richter scale occurred in Japan on March 2011 which was followed by 5 to 8 meters tsunami wave hitting east coast of Tohoku including Fukushima Nuclear Power Plant. The disaster caused reactor meltdown which led to explosion and emission of radioactive substances to environment. Right after the accident, radionuclide were detected in air outside of restricted zone (Radius $>20 \mathrm{~km}$ ) for 14-25.3 $\mu \mathrm{Sv} / \mathrm{h}$, inside of restricted zone (Radius $<20 \mathrm{Km}$ ), radionuclide were detected in air for $0.5-110 \mu \mathrm{Sv} / \mathrm{h}$ and in soil for $6.8-106 \mathrm{~Bq} / \mathrm{m} 3$ (I-131), $1.8-3.7 \times 105 \mathrm{~Bq} / \mathrm{m} 3$ (Cs-134), and 3.3-380,000 Bq/m3 (Cs-137)[1], [2].

Fukushima City which is located $70 \mathrm{Km}$ from Fukushima Dai-Ichi Nuclear Power Plant, received a high amount of radionuclides deposition. Based on survey conducted by Ministry of Education, Culture, Sport, Science and Technology Japan [1], 94,700 Bq/ $/ \mathrm{m}^{2}$ of radiocesium was deposited on the capital city of Fukushima Prefecture. Furthermore, the deposited radiocesium in urban area was transported mostly by rain-run off mechanism into other location such as sewer system. $6,158 \mathrm{~Bq} / \mathrm{Kg}$ of $\mathrm{Cs}-137$ was

Manuscript received December 10, 2013; revised February 26, 2014 This work was supported in part by Kyoto University Global COE.

M. A. Pratama, M. Yoneda, Y. Shimada, and Y. Matsui are with the Department of Environmental Engineering, Kyoto University, Kyoto, Japan (e-mail: raga@ risk.env.kyoto-u.ac.jp, yoneda@ risk.env.kyoto-u.ac.jp, shimada@ risk.env.kyoto-u.ac.jp, ymatsui@ risk.env.kyoto-u.ac.jp),

Y. Yamashiki is with Graduate School of Advanced Integrated Studies in Human Survivability, Kyoto University, Kyoto, Japan (e-mail: yamashiki.yosuke.3u@kyoto-u.ac.jp). detected from sludge of waste water treatment plant (WWTP) on September 2011. In current time, the produced sludge still contains Cs-137 at $100-600 \mathrm{~Bq} / \mathrm{Kg}$. Such a problem that makes the operating company have to store the sludge since it is prohibited to be transported to landfill facility due to high radioactive content.

Previous studies had been explained and investigated behavior of radionuclide in urban environment [3], [4]. Study conducted by Carlsson [5], the initial fraction of radionuclide, mobile form, which deposited in surface ground would be instantaneously migrated into water body. The remaining part would be fixated at rate depending on the material where radionuclide is deposited and would be accumulated in the storage compartment available for delayed migration.

There are two mechanisms which could explain the process which are rapid wash off and long term wash off. Rapid wash off is occurred at small time scales (day, month, season), involving mobile form of radionuclide, which the rate is increased after heavy rainfall, flood and snowmelt [6].The occurrence of rapid wash off is intense during the few weeks after deposition [7]. Thereafter, the rate of wash off will be decreased but still active within years or decades referred as "long term" wash off. IAEA [8] refers this process as "peak and tail", where "peak" represents the rapid wash off and "tail" represents the long term wash off.

Gallego [9] investigated migration of radionuclide in urban area based on Chernobyl accident data by developing model for Radionuclide Migration in Urban Environment and Drainage System (MUD). The model is divided into two sub-models which are urban sub-model and sewer system sub-model. The study showed a good result in case of Lund and Galve, Sweden. Therefore this study tried to find out the possibility of MUD application in case of Fukushima City. The aim of this paper is to simulate and investigate the migration of Cs-137 from urban area of Fukushima City into WWTP of the city. The key parameter in this study is activity concentration of Cs-137 in sludge of WWTP. The result of the model will be compared to observed data of activity concentration.

\section{DESCRIPTION OF THE MODEL}

MUD is multi compartment model which analyzes migration of radionuclide from one compartment into another where the migration process is represented by transfer rate. Moreover, beside transfer between compartment, decay process is also counted for describing dynamic of radionuclide in one compartment. Gallego [9] constructed the governing equation for MUD which can be expressed as: 


$$
\frac{d A_{s}}{d t}=\left(\sum_{r=1}^{n} R_{r \rightarrow s}\right) A_{r}-\left(\sum_{r=1}^{n} R_{s \rightarrow r}\right) A_{s}-\lambda_{s} A_{s}+I_{s}
$$

where $A_{\mathrm{s}}$ and $A_{r}$ are the activity present in compartment s and r respectively at time $t . R_{r_{\rightarrow} s}$ and $R_{s \rightarrow r}$ represent transfer rate from compartment $r$ to $s$ and $s$ to $r$. $\lambda$ represents the specific decay rate of radionuclide, whereas $I_{s}$ represents the initial input of radionuclide in the compartment. The calculation has been programmed by using Fortran ${ }^{\circledR}$.

\section{A. Urban Sub-Model}

Sub-model urban divides urban area based on covering material of surface ground where radionuclide is deposited. Four types of surface ground are used in this model, namely tree, paved, wall and roof which are classified as built-up area Each type of surface ground represents one compartment. Processes calculated in sub-model are:

- Deposition. Deposition of Cs-137 becomes an input of this model

- Fixation. As Cs-137 deposited on surface ground, the radionuclide is in mobile form. Then after it would be fixated into fixed form.

- Wash off process. Migration of radionuclide from surface ground into sewer system naturally occurs due to wash off process facilitated by surface run-off. About 10-70\% of mobile form of radionuclide would be washed off by first heavy rain[10].

- Leaves fall. For tree compartment, besides washed off process, migration of radionuclide caused by leave fall is also considered in MUD.

- Decontamination activities. Local community conducted decontamination on roof and paved area on August 2011. This activity significantly change amount of radionuclide in surface ground.

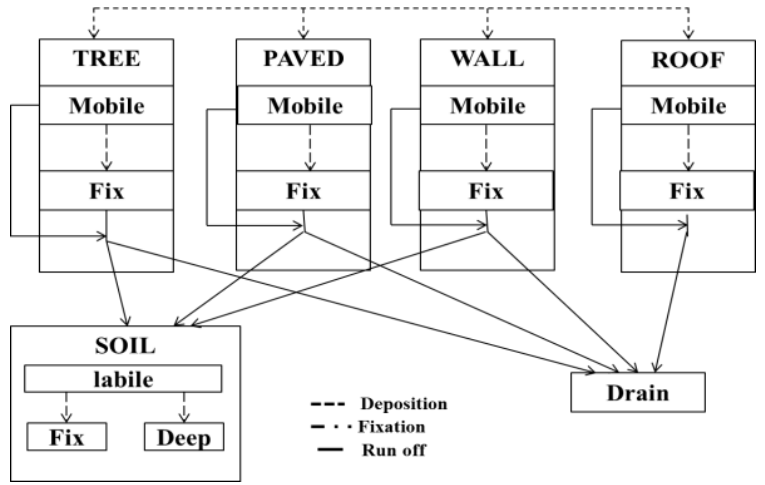

Fig. 1. Structure of urban sub-model.

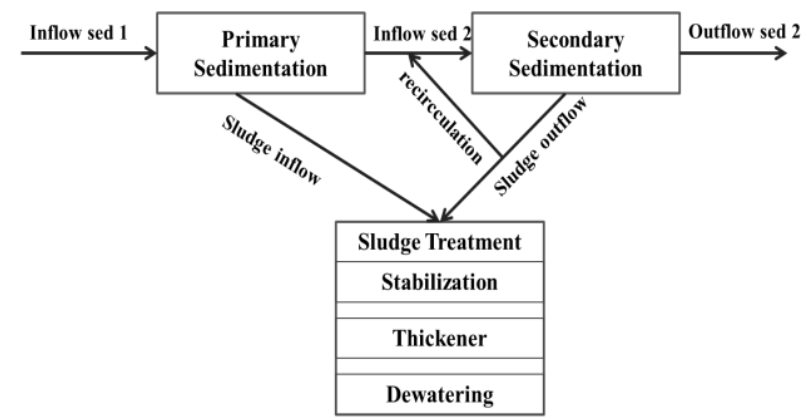

Fig. 2. Structure of WWTP Sub-model.
Run-off mostly plays as an important role for radionuclide migration from surface ground to sewer system. Some fraction of run-off flows into sewer system. It was estimated by curve fitting method, about $0.75 \%$ of surface run off infiltrate separate sewer system. The structure of urban sub-model which includes all of the considered process is shown in Fig. 1.

\section{B. WWTP Sub-Model}

After radionuclide enters sewer system, about $75-80 \%$ of it would be adsorbed by suspended solid which is contained in waste water [10]. Then after, radionuclide enters WWTP where treatment units would significantly affect amount of radionuclide in waste water. Since significant part of radionuclide is attached with suspended solid particle, sub-model WWTP only involves treatment unit that affects suspended solid content. Typically, those units are primary sedimentation, secondary clarifier and sludge treatment unit (Fig. 2).

Processes calculated in WWTP sub-model are:

- Sedimentation process conducted by primary and secondary sedimentation

- Sludge treatment conducted by sludge thickener and dewatering unit

- Recirculation of sludge that is produced by secondary sedimentation.

The amount of radionuclide which is attached into solid particle at final form of sludge would be the end point of this model. The detail of calculation used in MUD is explained in Gallego [9].

\section{STUDY LOCATION}

\section{A. Catchment Area of the Sewer System}

WWTP of Fukushima City is located at the south part of Fukushima City. Providing service for 269,100 inhabitants and covering 76,200 $\mathrm{Ha}$, the plant receives 36,000-42,000 $\mathrm{m}^{3} /$ day. Fig 3 shows location of WWTP in Fukushima City. Four districts are served by this WWTP which are Fukushima City, Date City, Koori Town, Kunimi Town (Fig. 3). The sewer system flow municipal waste water by $56.2 \mathrm{~km}$ of pipe, separated with drainage system and distributed within service area with range of diameter from 400-1,650 mm.

TABLE I: COVERAGE AREA OF WWTP, LAND COVER AND AVERAGE DEPOSITION OF CS-137 IN FUKUSHIMA CITY [11]-[12]

\begin{tabular}{|l|c|c|c|}
\hline District & $\begin{array}{c}\text { Area } \\
\mathrm{Ha}\end{array}$ & $\begin{array}{c}\text { Percentage } \\
\text { of Roof } \\
(\%)\end{array}$ & $\begin{array}{c}\text { Average Deposition } \\
\text { of Cs-137 }\left(\mathrm{Bq} / \mathrm{m}^{2}\right)\end{array}$ \\
\hline & & & \\
\hline Fukushima City & 101,706 & 70 & $101,705.90$ \\
\hline Date City & 210,412 & 48 & 210,412 \\
\hline Koori Town & 171,476 & 46 & $171,476.10$ \\
\hline Kunimi Town & 157,022 & 43 & $157,021.90$ \\
\hline
\end{tabular}

$70 \%$ of land cover of the catchment area is built up where the density of building in Fukushima City is higher than the other districts (Table I). About $70 \%$ of built up area in Fukushima City is occupied by roof. In the other hand, roof 
only covers $43 \%$ of built up area in Kunimi Town. Deposition of radionuclide data were also collected from each district (Table I). Deposition of Cs-137 in Date City is the highest among other areas whereas Fukushima City received the lowest deposition of Cs-137.

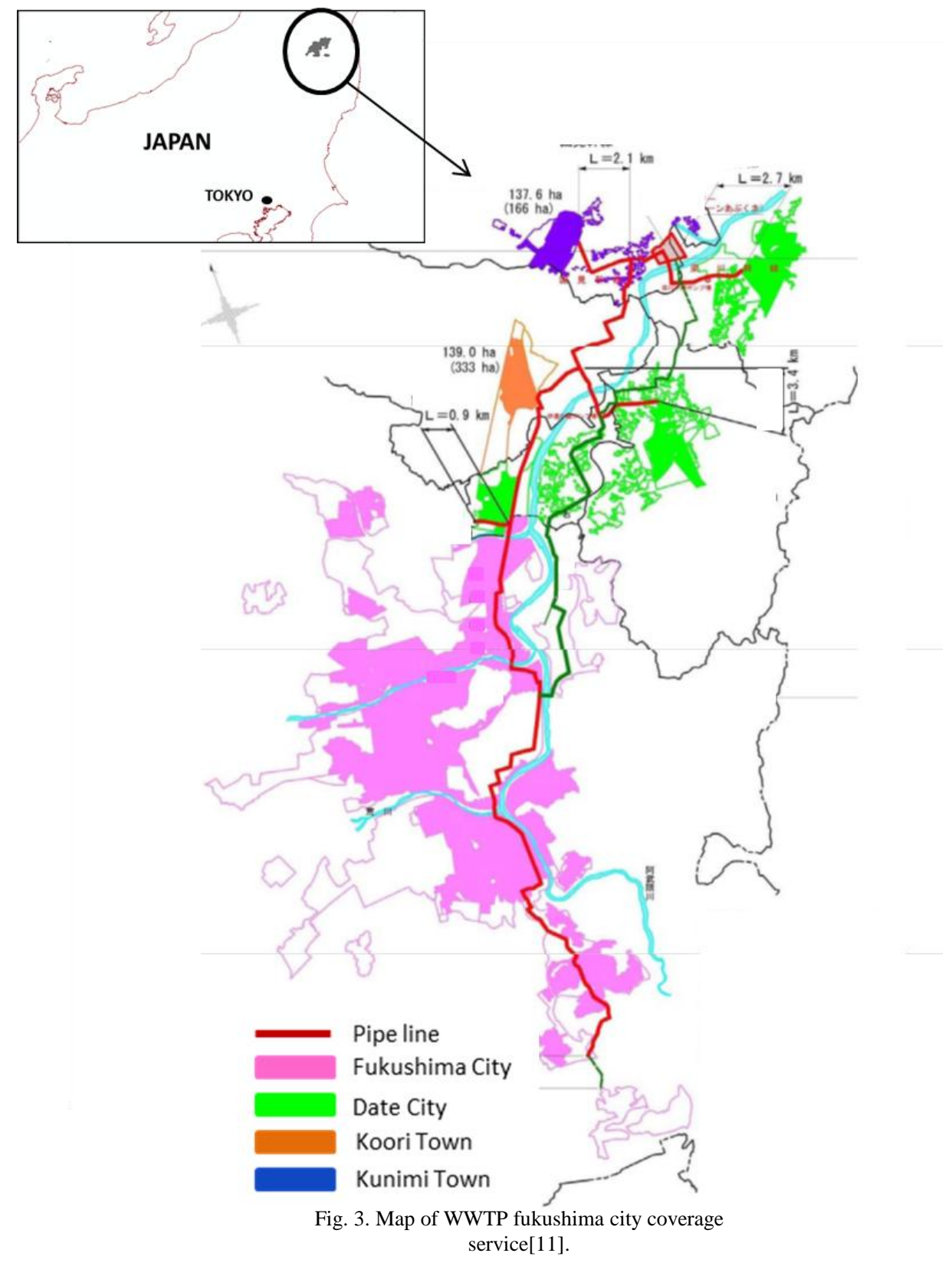

\section{B. WWTP of Fukushima City}

WWTP Fukushima City uses physical-biological and chemical treatment for removing contaminant from waste water. The configuration of treatment plant is started by screening for relatively bigger size contaminant. Primary sedimentation is used to remove suspended solid. Then after, activated sludge and secondary clarifier would remove organic contaminant and the remaining suspended solid. Chlorination is used to remove microorganism content in the wastewater before it is discharge into receiving water body. Utilization of primary sedimentation and secondary clarifier would consequently produce sludge. Sludge treatment unit used in this plant consist of sludge stabilization and dewatering to reduce its water content before transported into landfill facilities for final disposal.
Seasonal trend of inflow rate was observed based on data of 2009-2013 periods (Table II). Inflow rate is relatively higher during high frequency of rainfall (September/October). Although the sewer uses separate system, surface runoff which is resulted from rainfall might enter the pipe line through gap in manhole, crack within the pipe system, old joint, etc. Despite the seasonal variation of inflow rate, suspended solid loading into the WWTP tends to be consistent. Based on data from 2009-2013 periods, average inflow of suspended solid into WWTP was in range of $122-145 \mathrm{mg} / \mathrm{l}$.

Related to sludge production, performance of primary sedimentation and secondary clarifier were monitored based on data from 2009-2013. The average of suspended solid removal of primary sedimentation is $66 \%$ whereas the removal rate of secondary clarifier is $94 \%$ (Fig. 4). 
Comparing both values to default value used in MUD $(60 \%$ and $85 \%$ respectively) indicates both units have a good performance.

TABLE II: AVERAGE DAILY INFLOW RATE OF WASTEWATER AND SUSPENDED SOLID IN WWTP FUKUSHIMA CITY [11]

\begin{tabular}{|c|c|c|}
\hline Month & $\begin{array}{c}\text { Average inflow } \\
\text { rate ( } \text { m }^{3} / \text { day) }\end{array}$ & $\begin{array}{c}\text { Average SS } \\
\text { inflow (mg/l) }\end{array}$ \\
\hline Jan & 39,647 & 135 \\
\hline Feb & 42,805 & 129 \\
\hline Mar & 38,115 & 122 \\
\hline Apr & 36,640 & 130 \\
\hline May & 35,712 & 139 \\
\hline Jun & 38,861 & 145 \\
\hline Jul & 38,538 & 134 \\
\hline Aug & 39,858 & 127 \\
\hline Sep & 42,734 & 131 \\
\hline Oct & 40,876 & 129 \\
\hline Nov & 41,355 & 133 \\
\hline Dec & 39,186 & 127 \\
\hline
\end{tabular}

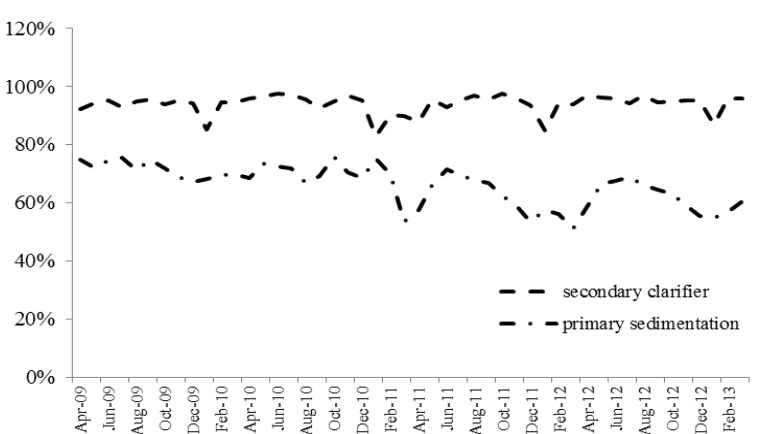

Fig. 4. Monthly average of suspended solid removal of primary sedimentation and secondary clarifier in WWTP Fukushima city [11]

Following Fukushima Dai-Ichi Nuclear Power Plant accident, the WWTP has to deal with the high amount of radiocesium content in its sludge. Table 3 shows empirical data of monthly average of activity concentration for Cs-137 and Cs-134 in dewatered sludge. It is shown that activity concentration of Cs-137 and Cs-134 was relatively high during June to September period compared to other months. It is expected that seasonal variation factor plays as the important factor on fluctuation of Cs-137 and Cs-134 activity concentration since the trend has high correlation with rainfall depth data.

TABLE III: MONTHLY AVERAGE OF CS-137 AND CS134 ACTIVITY CONCENTRATION OF DEWATERED SLUdGe OF WWTP FuKUSHIMA City [13]

\begin{tabular}{|c|c|c|c|}
\hline Time & $\begin{array}{c}\text { Cs-137 } \\
(\mathrm{Bq} / \mathrm{kg})\end{array}$ & $\begin{array}{c}\text { Cs-134 } \\
(\mathrm{Bq} / \mathrm{kg})\end{array}$ & $\begin{array}{c}\text { Rainfall } \\
\text { depth } \\
(\mathrm{mm})\end{array}$ \\
\hline Jun-11 & 797.10 & 758.03 & 6.68 \\
\hline Jul-11 & 1104.77 & 1011.63 & 6.17 \\
\hline Aug-11 & 984.74 & 880.81 & 6.17 \\
\hline Sep-11 & 543.93 & 479.37 & 6.17 \\
\hline Oct-11 & 275.29 & 226.13 & 6.08 \\
\hline Nov-11 & 197.57 & 159.53 & 5.96 \\
\hline Dec-11 & 192.35 & 155.30 & 5.96 \\
\hline Jan-12 & 212.97 & 168.71 & 5.96 \\
\hline Feb-12 & 225.38 & 180.52 & 6.70 \\
\hline Mar-12 & 352.23 & 261.39 & 6.70 \\
\hline Apr-12 & 200.07 & 140.57 & 6.73 \\
\hline May-12 & 242.55 & 191.74 & 6.73 \\
\hline
\end{tabular}

Parameter values for calculating the migration of cesium in urban area and WWTP are available in appendix.

\section{MOdEL TeST}

In the following calculation, it is assumed that fall out is a single event after the accident. Although many reports mentions fall out of radionuclides occurred continuously in some period, the amount of radionuclides after first event was not significant compared to first fall out where 2-3 orders of difference were observed. Therefore, single event of fall out was used and the following fall out could be neglected. However, fall out data was recorded at 26 May of 2011 which is more than one month after the accident. Thus, the real amount of Cs-137 which was deposited right after the accident was unknown. This problem will lead into uncertainty in the result of the model.

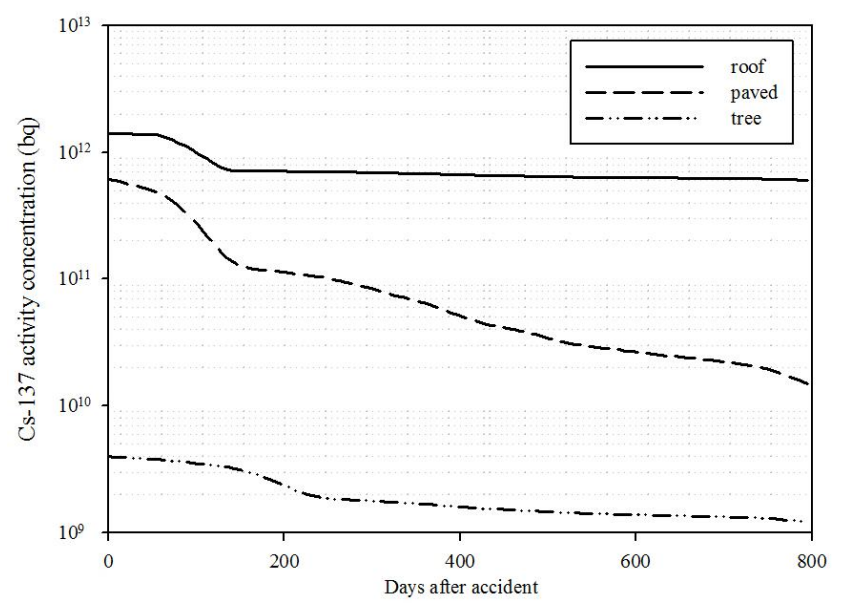

Fig. 4. Model result for dynamic of Cs-137 in tree (a). paved (b). roof and wall (c). compartment

Based on Fig. 4a, Fig. 4b, and Fig. 4c, one can note that:

- Due to the value of removal rate of fixed component by rainfall, the activity of Cs-137 in roof compartment is more persistent than other compartments. The figure shows after first heavy rain which is happened in $8^{\text {th }}$ day after deposition, the activity of Cs-137 is relatively stable over time. The value of removal rate which is only $0.0001 \mathrm{~mm}^{-1}$ could explain the persistency of Cs-137 activity in roof compartment.

- Two events of rapid decreasing of Cs-137 activity in tree compartment were occurred which are: heavy rain at $8^{\text {th }}$ day after deposition which washed of $40 \%$ of mobile form and Leaves fall during autumn season. Radionuclides which is attached on the surface of leaves and fixated on it migrated into surface ground and reduce the activity of $\mathrm{Cs}-137$ in tree compartment. It is estimated that $60 \%$ of radionuclide attached on the leaves migrated into surface ground under leaves fall process.

- In paved compartment, increasing of activity was occurred during first autumn after the accident since the compartment received Cs-137 which was transported by leaves fall process. This Cs-137 was in mobile form at first, then it was fixated into pave material under fixation 
rate of $0.23 \mathrm{day}^{-1}$. The following migration process is undergone under wash-off process by run-off.

- During August of 2011, decontamination activity was carried out by the local community. Paved and roof were decontaminated by using high pressure water hosing. It was estimated that the activity was removed $50 \%$ of Cs-137 contained in paved and roof compartment. Rapid decrement of Cs 137 activity during August 2011 is showed in fig.4 for roof and paved compartment.

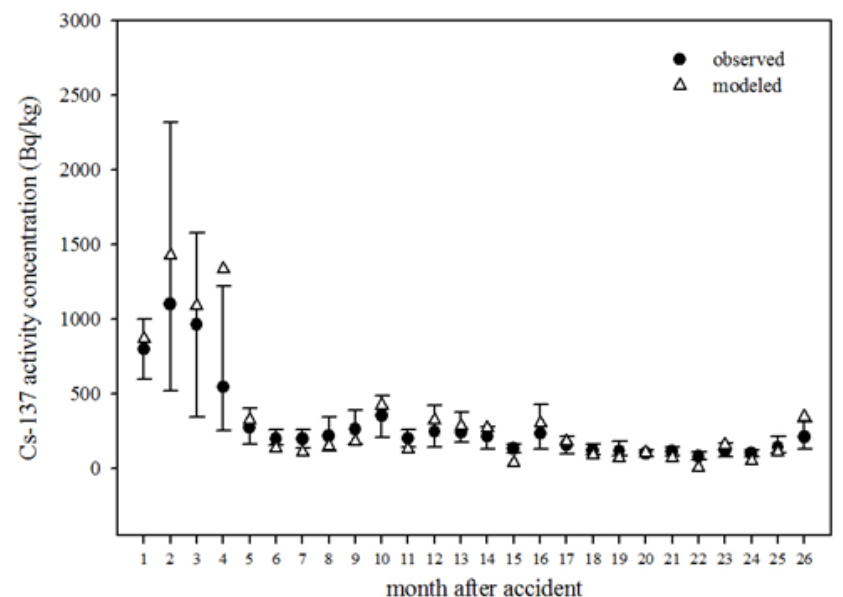

(a)

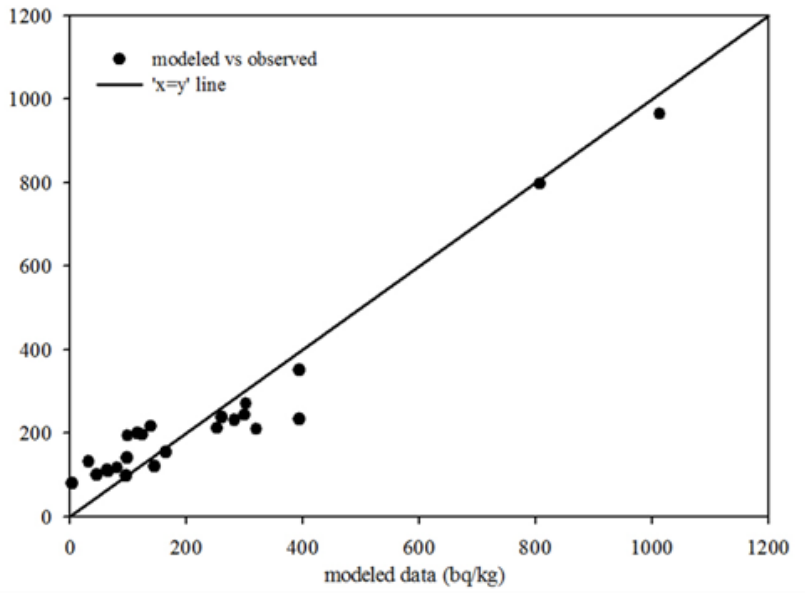

(b)

Fig. 5. Comparison between result of the model and empirical data (a) and scattered plot of modeled data And empirical data compared to $x=y$ line (b).

Based on Fig. 5a and Fig. 5b, one can note:

- The result of the model showed that $85 \%$ of the modeled data are in the range of 10-90 percentiles of observed data. Both of the data are in the same order except in September of 2011 where the calculation result was one order higher than the empirical datum. High error was also observed on months with low rainfall rate where the result of the model is 1.5-2 times lower than the empirical data. The gap between result of model and empirical data roughly corresponds to the uncertainty in the empirical values.

- Fig. 5b shows almost all of the plot result of empirical data and modeled data are around the $\mathrm{x}=\mathrm{y}$ line. With $\mathrm{R}^{2}$ value of 0.84 , it could be noted that the model could explain seasonal variability of observed data.

- September in Japan is characterized by high rainfall rate and high storm event. Operation performance of sedimentation unit is affected during storm event. This is caused by overload of suspended solid entering WWTP. During storm, removal rate of suspended solid by sedimentation decreases by $30-50 \%$. This problem is not considered in this study since the storm data is unavailable, thus the removal rate of suspended solid used during storm event is removal rate in normal condition (66\% for primary sedimentation and $94 \%$ for secondary clarifier). Overestimation of removal of suspended solid would lead to overestimation of sludge production and removal of radioactivity attached to suspended solid. Finally, overestimation of radioactivity in sludge of WWTP would be occurred. Storm event is one of the uncertainties in this study.

- It has to be noted that with the persistency of fixed form Cs-137 in wall and roof, the flux of radionuclide into WWTP would be continuously occured. However, the amount of flux would gradually decrease due to decay, washed off and decontamination process.

\section{CONCLUSION AND COMMENTS}

This paper has applied MUD which was developed based on Chernobyl accident data in Fukushima City case. MUD estimates discharge of radionuclide from urban area by natural (washed off by run off) and forced (washing, brushing, etc.) decontamination process into natural receiving water body such as river and artificial receiving water body such as drainage and sewer system. The estimation is calculated by using multi-compartment model and programmed by fortran®.

MUD consists of urban sub model and WWTP sub-model. Urban Sub-model divides urban area into four types which are paved, tree, rood and wall. Output of the model is discharge of radionuclide into sewer system. Sub-model WWTP considered primary sediment, secondary clarifier and sludge treatment as factor affecting amount of radionuclide in waste water. Output of WWTP sub-model is concentration of radionuclide in sludge.

In this study, all of obligatory parameter value in Urban Sub-Model was not changed whereas in WWTP sub-model, since the operational data of WWTP Fukushima City is available, the value of some operational parameter had been calibrated. Despite using value of parameter developed based on Chernobyl accident, the model gives a fair result and could be relied for rough prediction. Several uncertainties have to be dealt in this model such as storm effect and initial deposition data.

Improvement of the model could be done by measuring fraction of run-off that enters sewer system by analyzing inflow rate of WWTP during dry and wet weather. Moreover, since poor result occurred during low rainfall season, another source of Cs-137 has to be identified for improving the result 
of the model.

\section{APPENDIX}

Parameter value used in MUD:

\begin{tabular}{|l|c|c|}
\multicolumn{1}{|c|}{ Definition } & Unit & Value \\
\hline Total area drained by the sewage & $\mathrm{m} 2$ & $76,200,000.00$ \\
\hline Population (number of inhabitants) & inhab & $269,100.00$ \\
\hline $\begin{array}{l}\text { Built-up fraction: fraction of drainage } \\
\text { area }\end{array}$ & - & 0.7 \\
\hline $\begin{array}{l}\text { Fraction of built-up area occupied by } \\
\text { roofs }\end{array}$ & - & 0.75 \\
\hline $\begin{array}{l}\text { fraction of runoff from wall to } \\
\text { drainage }\end{array}$ & - & 0.625 \\
\hline $\begin{array}{l}\text { fraction of runoff from wall to } \\
\text { sewerage }\end{array}$ & - & 0.0075 \\
\hline fraction of runoff from wall to soil & - & 0.3 \\
\hline $\begin{array}{l}\text { fraction of runoff from tree to } \\
\text { drainage }\end{array}$ & - & 0.375 \\
\hline $\begin{array}{l}\text { fraction of runoff from tree to } \\
\text { sewerage }\end{array}$ & - & 0.075 \\
\hline Fraction of runoff from tree to soil & - & 0.55 \\
\hline Fraction of runoff from paved to drain & - & 0.725 \\
\hline $\begin{array}{l}\text { Fraction of runoff from paved to } \\
\text { sewerage }\end{array}$ & - & 0.075 \\
\hline Fraction of runoff from paved to soil & - & 0.2 \\
\hline $\begin{array}{l}\text { Removal rate of suspended solid on } \\
\text { primary sedimentation }\end{array}$ & $\%$ & 66 \\
\hline $\begin{array}{l}\text { Removal rate of suspended solid on } \\
\text { secondary sedimentation }\end{array}$ & $\%$ & 94 \\
\hline
\end{tabular}

\begin{tabular}{|c|c|c|}
\hline \multicolumn{3}{|c|}{ GENERIC PARAMETER VALUE [9] } \\
\hline Definition & Unit & Value \\
\hline $\begin{array}{l}\text { Fixation rate of mobile component in } \\
\text { paved areas }\end{array}$ & $/ \mathrm{d}$ & 0.23 \\
\hline $\begin{array}{l}\text { Fixation rate of mobile component in } \\
\text { roofs }\end{array}$ & $/ \mathrm{d}$ & 0.23 \\
\hline $\begin{array}{l}\text { Fixation rate of mobile component in } \\
\text { walls }\end{array}$ & $/ \mathrm{d}$ & 0.23 \\
\hline $\begin{array}{l}\text { Fixation rate of mobile component in } \\
\text { trees }\end{array}$ & $/ \mathrm{d}$ & 0.23 \\
\hline $\begin{array}{l}\text { Radioactivity fraction from trees fixed } \\
\text { on leaves }\end{array}$ & - & 0.85 \\
\hline $\begin{array}{l}\text { Radioactivity fraction from leaf fall to } \\
\text { soil }\end{array}$ & - & 0.6 \\
\hline $\begin{array}{l}\text { Migration rate from surface soil to } \\
\text { labile }\end{array}$ & - & 0.000665 \\
\hline $\begin{array}{l}\text { Migration rate from labile to fixed } \\
\text { form in soil }\end{array}$ & - & 0.0019 \\
\hline $\begin{array}{l}\text { Migration rate from fixed to labile } \\
\text { form in soil }\end{array}$ & - & 0.00021 \\
\hline $\begin{array}{l}\text { Migration rate from labile form in soil } \\
\text { to depth }\end{array}$ & - & 0.0000385 \\
\hline $\begin{array}{l}\text { Removal rate of fixed component in } \\
\text { paved area }\end{array}$ & $/ \mathrm{mm}$ & 0.00125 \\
\hline $\begin{array}{l}\text { Removal rate of fixed component in } \\
\text { roof area }\end{array}$ & $/ \mathrm{mm}$ & 0.0001 \\
\hline $\begin{array}{l}\text { Removal rate of fixed component in } \\
\text { walls area }\end{array}$ & $/ \mathrm{mm}$ & 0.000001 \\
\hline $\begin{array}{l}\text { Removal rate of fixed component in } \\
\text { trees area }\end{array}$ & $/ \mathrm{mm}$ & 0.00069 \\
\hline $\begin{array}{l}\text { Fraction mobile component of paved } \\
\text { removed by first heavy rain }\end{array}$ & - & 0.6 \\
\hline $\begin{array}{l}\text { Fraction mobile component of roof } \\
\text { removed by first heavy rain }\end{array}$ & - & 0.6 \\
\hline $\begin{array}{l}\text { Fraction mobile component of walls } \\
\text { removed by first heavy rain }\end{array}$ & - & 0.4 \\
\hline
\end{tabular}

\begin{tabular}{|l|c|c|}
\hline \multicolumn{1}{|c|}{ Definition } & Unit & Value \\
\hline $\begin{array}{l}\text { Fraction mobile component of tree } \\
\text { removed by first heavy rain }\end{array}$ & - & 0.4 \\
\hline $\begin{array}{l}\text { Fraction of roof component removed } \\
\text { by decontamination activity }\end{array}$ & & 0.5 \\
\hline $\begin{array}{l}\text { Fraction of paved component } \\
\text { removed by decontamination activity }\end{array}$ & $1 / \mathrm{kg}$ & 0.5 \\
\hline partition coefficient & - & 3000 \\
\hline $\begin{array}{l}\text { radioactivity attached to suspended } \\
\text { solid removed in primary }\end{array}$ & $\%$ & 0.5 \\
\hline primary sludge concentration & $\%$ & 4 \\
\hline secondary sludge concentration & - & 0.8 \\
\hline $\begin{array}{l}\text { radioactivity attached to suspended } \\
\text { solid removed in secondary }\end{array}$ & - & 0.75 \\
\hline dry solid after stabilitation & - & 0.65 \\
\hline dry solid after thickening & & 0.8 \\
\hline dry solid after dewatering & & 0.9 \\
\hline
\end{tabular}

\section{ACKNOWLEDGMENT}

Author thanks Kyoto University Global COE for financial support on publication of this study's result. Moreover, authors also thanks to Fukushima Prefecture Sewerage Public Corporation for providing data that were significantly useful in this study.

\section{REFERENCES}

[1] Ministry of Education, Culture, Sport, Science and Technology Japan. Readings at Monitoring Post out of $20 \mathrm{Km}$ Zone of Fukushima Dai-ichi NPP Mei 2011, Retrieve from Readings of integrated Dose at Monitoring Post out of $20 \mathrm{Km}$ Zone of Fukushima Dai-ichi NPP. [Online].

http://www.mext.go.jp/english/incident/1308050.htm

Available:

[2] Ministry of Education, Culture, Sport, Science and Technology Japan. Readings at Monitoring Post inside $20 \mathrm{Km}$ Zone of Fukushima Dai-ichi NPP Mei 2011, Retrieve from Readings of Radioactivity level inside of the $20 \mathrm{~km}$ zone of Fukushima Dai-ichi NPP. [Online] Available : http://www.mext.go.jp/english/incident/1305397.htm

[3] K. G. Andersson, J. Roed, H. G. Paretzke, and J. Tschiersch, "Modelling of the radiological impact of a deposit of artificial radionuclides in inhabited areas," Radiation Protection Research Action, vol. 3, pp. 4195-4206. 1978.

[4] J. Roed and P. Jacob, "Deposition on Urban surfaces and subsequent weathering," presented at the Seminar on Methods and Codes for Assessing the Off-Site Consequences of Nuclear Accidents, 1990.

[5] C. Sten, "A model for the movement and loss of 137-Cs in a small watershed," Health Physics, vol. 34, pp. 33-73, 1978.

[6] P. Spezzano, S. Bortoluzzi, R. Giacomelli, and L. Massironi, "Seasonal variations of $137 \mathrm{Cs}$ activities in the dora Baltea river after the Chernobyl accident," J. Environ. Radioact, vol. 22, pp. 77-88, 1994.

[7] W. Jacobi, "Transfer of fission products from atmospheric fallout into river water," in Proc. International Symposium on 'Radioecology Applied to the Protection of Man and His Environment, CEC, Luxembourg, pp. 1153-1165, 1971.

[8] Generic Models for Use in Assessing The Impact of Discharges of Radioactives Substance into The Environment, IAEA Technical Report Series, no.19, pp. 29, 2001,

[9] E. Gallego, "MUD: a model to investigate the migration of 137Cs in the urban environment and drainage and sewage systems," J. Environ. Radioact, vol. 85, pp. 247-264, 2006.

[10] Handbook of Parameter Values for The Prediction of Radionuclide Transfer in Temperate Environments, Technical Reports Series, no. 364, Vienna,1994, pp. 34

[11] Annual Report of Maintenance of Sewer System, Nihonmatsu Treatment Group, Japan, 2012, pp. 1-73.

[12] Nucreal Regulation Authority Japan. (2013). [Online]. Available : http:// www. radb.jaea.go.jp/mapdb/en/

[13] F. Prefecture. Measurement Result of Radioactive Substance from Dewatered Sludge of WWTP in North Region of Fukushima Prefecture. [Online]. 
http://wwwcms.pref.fukushima.jp/download/1/gesuidouka_kenpoku odei250718.pdf

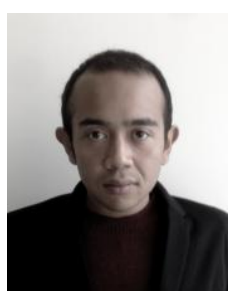

Mochamad Adhiraga Pratama was born in Jakarta Indonesia on 28 November 1986. He obtained bachelor degree on environmental engineering (B.Eng) from Bandung Institute of Technology (ITB), Bandung, Indonesia in 2009. In 2011, master degree on environmental engineering with specialization on environmental health and safety (M.Eng) was obtained from the same university.
He was the staff of Directorate of Infrastructure Development of ITB, Bandung, Indonesia from 2010-2012. From February to March, 2013, he was an intern in International Agency of Atomic Energy (IAEA), Vienna, Austria. Currently, he is a doctoral student in Environmental Engineering Department of Kyoto University and member of Environmental Risk Analysis Laboratory, Kyoto University, Kyoto, Japan. He is interested on analyzing environmental and health risk of pollutant such as organochlorine pesticide, heavy metal and radioactive substance. Currently he is working on simulation and modeling of radionuclide pollution in catchment area of Abukuma River, Japan. 